\title{
How risk communication could have reduced controversy about school closures in Australia during the COVID-19 pandemic
}

\author{
Julie Leask $k^{\mathrm{a}, \mathrm{c}}$ and Claire Hooker ${ }^{\mathrm{b}}$ \\ a Susan Wakil School of Nursing and Midwifery, Faculty of Medicine and Health, University of Sydney, NSW, Australia \\ b Sydney Health Ethics, Faculty of Medicine and Health, University of Sydney, NSW, Australia \\ c Corresponding author: julie.leask@sydney.edu.au
}

\section{Article history}

\section{Publication date: June 2020}

Citation: Leask J, Hooker C. How risk communication could have reduced controversy about school closures in Australia during the COVID-19 pandemic. Public Health Res Pract. 2020;30(2):e3022007. https://doi.org/10.17061/phrp3022007

\section{Key points}

- There are well-established principles for effective risk communication in situations of high uncertainty and fear. Good risk communication can reduce or mitigate the intensity of public responses to hazards in a health emergency

- Failure to utilise these principles resulted in a divisive and confusing public debate about whether or not schools should be closed in Australia in response to the COVID-19 pandemic, contributing to a prolonged period of remote learning for most students, associated with significant educational and social costs

- We recommend governments prepare for two-way communication by listening to stakeholders, communicate early and frankly, share information and the questions they are exploring, and respect and trust their audiences

\section{Abstract}

Although there has been consistent evidence indicating that school closures have only limited efficacy in reducing community transmission of coronavirus disease 2019 (COVID-19), the question of whether children should be kept home from school has attracted extensive and often divisive public debate in Australia. In this article we analyse the factors that drove high levels of concern among parents, teachers and the public and led to both demands for school closures in late March 2020, and to many parents' reluctance to return their children to school in May 2020. We discuss how the use of wellestablished principles of risk communication might have reduced much of this community concern. Then we set out a range of practical suggestions for communication practices that build trust and hence diminish concerns in relation to managing schools over the long term of the COVID-19 pandemic.

\section{Background}

There is a long history of school closures in infectious disease outbreak and pandemic control. ${ }^{1}$ Research on influenza finds that for pro-active school closures to be effective in reducing the transmission of infection, they should be done early, at scale and for a prolonged period. ${ }^{2}$ However, weighing heavily against these potential benefits are known and very significant social and economic impacts. ${ }^{3}$ These include economic losses ${ }^{4}$, job insecurity and income loss for caregivers forced to stay at home, a related loss of the healthcare workforce due to childcare demands, self-caring of children younger than 13 years, and differential impacts for disadvantaged children. ${ }^{1}$ Disruption to the education of children has also been described following school closures. ${ }^{5}$

The questionable net benefit of school closures may be further reduced when considering the characteristics of COVID-19. Early evidence suggested much lower attack rates in children and young people aged under 19, compared with influenza. ${ }^{6,7}$

Given this combination of factors, the Australian Government's key decision-making committee for health emergencies, the Australian Health 
Protection Principal Committee (AHPPC), advised against proactive school closures on 17 March 2020, stating:

"The Committee's advice is that pre-emptive closures are not proportionate or effective as a public health intervention to prevent community transmission of COVID-19 at this time."8

The statement outlined experience from overseas, existing evidence on transmission in children and the serious impacts of closing schools. It presented suggestions for minimising transmission in schools and noted that advice would continue to be reviewed at daily meetings of the AHPPC. It did not contain references to the evidence sourced and only provided general descriptions of study findings.

\section{Community response}

The AHPPC statement, and statements of reassurance from government representatives at media conferences, were the only information the Australian Government provided at that time. Amid high public anxiety about impending outbreaks of COVID-19, healthcare workers and experts weighed in, including Dr Norman Swan, a well-known, medically qualified journalist at the Australian Broadcasting Corporation.

"I'm getting a lot of questions from parents saying,

'Should I keep my kid home?' The thing about keeping your child home, the risk to your child is low. But it's a public health measure, because children spread the virus and they can spread it to teachers and so on and into the community. And my feeling is, to be blunt, we're dicking around and we've just got to shut stuff down now."

A chorus of community, parent and stakeholder voices rose in support of closing schools with hashtags such as \#closeschoolsnow appearing on Twitter.

These events occurred at the time when Australia began to ramp up its COVID-19 control strategies amid predictions that healthcare systems would be overwhelmed, and a sharp escalation in concerns among health professionals and the public about the threat of coronavirus in Australia. ${ }^{10}$

In Australia, state and territory governments have jurisdiction over primary and secondary schooling, and pressure was placed on these governments to diverge from Federal Government pandemic management decisions. The Australian Government's recommendation to keep schools open was disseminated alongside announcements of increasing social distancing measures, such as banning gatherings of more than 100 people. ${ }^{11}$ The inferred exemption of schools from these measures generated contradictions in messaging, creating confusion for parents, school staff and the community.

\section{The impact of 'fright factors'}

This scenario represented a near perfect storm of 'fright factors' that have been identified in research on risk perception as driving up people's fear while reducing their trust in those who manage the risk. ${ }^{12,13}$ In this case, the fright factors included: that the issue affected the vulnerable (children, and also their grandparents); the hazard was coerced insofar as schooling is compulsory for children and teachers must remain at school; the outcome was dreaded; and the agent invisible, poorly understood by science and without expert agreement on management strategies. In the early phase of health emergencies, trust is a critical element, shown to influence whether people will accept new information and be compliant with infection prevention and control strategies. ${ }^{14}$ In a situation of high concern and high uncertainty, inconsistency in messaging erodes trust in officials' competence to manage the risk. This inconsistency increased as the federal and state/territory governments and prominent health commentators took differing positions on school closures.

By late March 2020, State Premiers began to act. In Victoria, school holidays were brought forward to begin on 24 March. By 30 March, state-run schools in Victoria, New South Wales (NSW), Australian Capital Territory (ACT), Queensland and Western Australia were closed for face-to-face learning or open only to children of essential workers or, tacitly, for families in particular need. This situation, including school holiday periods, persisted for 8 weeks, and longer in some jurisdictions.

School closures cause harms although these are not uniformly distributed. A range of studies and reviews are now documenting negative impacts of COVID-19-related school closures on children's educational outcomes and wellbeing. One report estimates that up to $46 \%$ of Australian children and young people are at risk from a range of adverse effects. ${ }^{15}$ One review estimated there would be a loss of 6 weeks of learning in numeracy and 4 weeks of learning in reading for Aboriginal and Torres Strait Islander students and those from lower socioeconomic backgrounds after two terms of COVID-19induced online schooling. ${ }^{16}$

\section{Re-opening of schools}

Despite these harms, there has been considerable resistance to re-opening schools following the successful suppression of COVID-19 in Australia throughout April 2020. The Australian Government has maintained a consistent stance that schools should be kept open. By May, the Prime Minister pushed further for a full return of all students to school, citing additional evidence from a NSW investigation of COVID-19 cases from 15 primary and secondary schools. The preliminary findings identified 9 initial cases occurring in students and 9 cases 
in teachers, from whom only two secondary cases were identified among 863 close contacts. ${ }^{17}$

This rhetoric and evidence were met with doubt and disagreement from parents and teachers. By early May 2020, the debate about when and how schools should re-open had become deeply politicised with a war of words between the Australian Minister for Education (in favour of schools being open) and the Victorian Premier (against reopening). The conditions and plans for a staged return to school varied greatly among states and territories, adding to inconsistency and confusion for the community. Ambiguity aversion - the tendency to favour the known over the unknown - drives people to be risk averse. ${ }^{18}$ It is therefore unsurprising that half of those surveyed in early May agreed that schools should teach remotely until the COVID-19 outbreak has passed. ${ }^{19}$ By the end of May, NSW, Queensland, Tasmania and the ACT had returned all students to fulltime, face-to-face teaching in state-run schools, bringing a new communication challenge of ensuring that all parties are aware of measures to mitigate risk, are informed of changes in a timely manner, and have realistic expectations.

Over March and April 2020, fear increased and trust diminished as a result of three primary factors: a lack of transparent access to information driving state and federal government policy on schools; a lack engagement with community concerns; and serious confusion and inconsistency in messaging.

\section{Principles of risk communication}

The principles of risk communication have much to offer the management of health and other emergencies particularly where uncertainty prevails. ${ }^{20}$ Many of these principles are clearly set out in the Australian Health Sector Emergency Response Plan for Novel Coronavirus (COVID-19). ${ }^{21}$ Adoption of them may have reduced the anger and fear that, by late May, continued to make schools a point of contention in Australia.

We advocate for the following:

\section{Prepare for two-way communication}

- A pandemic requires many different actors to work together in a way not usually done. Kickbusch, and Sakellarides note these "loosely coupled systems must move closer together" and that "the smart city builds these long before a crisis occurs". ${ }^{22}$ The clear inability to consult with the educational sector in way that was detailed and heard the impacts and concerns, harmed the capacity of federal and state/territory governments to address the issues with sufficient specificity. We recommend that systems for communicating between sectors are set up, simulated and refined prior to an emergency.
- Part of this preparation involves engaging trusted spokespeople from key stakeholder groups with whom governments have pre-established relationships and communication pathways, and with whom they can more rapidly consult as response strategies are developed.

\section{Communicate early, be frank and transparent}

- Communicate early and often, particularly when action may go against public demand. Public communication from AHPPC was released at the time when a public debate about schools remaining open had already begun, leaving governments in a reactive mode. Early communication, before or while decisions are being formed, builds trust rather than erodes it. It signals that the range of community concerns and questions are being considered by the governments. Here, experts can be given leeway by politicians to speak frankly with the public. Early communication continued to be in deficit by late May. For example, schools in NSW appeared to only become aware of a plan to return to full classroom teaching with 1 week's notice, after it was reported by the media. ${ }^{23}$

- Be clear and detailed in the evidence and rationale for a policy, and its underpinning values: models and studies used should be provided; if this is not possible, the source of information should be identified. Decision makers could communicate what questions are being considered by the government, expert advisers and stakeholders, and how they balance the potential harms against the potential benefits of closing schools. Leaders should acknowledge that trade-offs may be difficult to assess because some impacts are hard to measure and occur on different time scales. They should then communicate a plan for how they intend to mitigate harms arising from any strategy.

- Transparent criteria for the closure of schools and its reversal would create levels of predictability and enable planning and reduce the risk of politicisation. Studies show that people are more likely to trust a decision if they see the process of arriving at it as fair. ${ }^{24}$

- Be explicit and open about uncertainty. In a pandemic, governments must make decisions before adequate information is available to guide them. The limitations as well as utilities of all types of evidence should be acknowledged. Acknowledging uncertainty helps demonstrate to the public how convergence on a policy occurs despite these variations and increases trust. For example, there remains uncertainty about the degree of risk from full school attendance, particularly for adults working at schools. It is possible that while the risk is low, there may still be outbreaks. Communicators should try to avoid overconfident proclamations that schools are "safe", and rather communicate that they are considered safe enough 
in the face of overwhelming benefits of a full return to face-to-face teaching and strategies in place to reduce risk.

\section{Respect and trust your audience}

- Anticipate and tolerate early strong reactions. The schools issue was likely to arouse anxiety at a time when the public was receiving multiple emotive messages about the importance of social distancing measures. When risk appraisal is high and fear aroused, people can be given actions to follow. ${ }^{25} \mathrm{~A}$ set of actions for minimising the already low risk in schools was released by AHPPC on 16 April 2020, 29 days after its initial advice to keep schools open.

- Empathy should characterise communication in a situation of fear and anger, avoiding a tone of admonishment or attempts to delegitimise public concern. Inauthentic empathy immediately reduces trust. To be genuine, leaders should comprehend and reflect the fears and concerns of those affected and demonstrate in its content a comprehension of the lifeworld of the affected person.

- Emphasising benefits can connect a policy with public values. However, communicating benefits can backfire if affected groups (such as parents or teachers with health concerns) feel they have not been consulted and that their concerns and needs have not been taken into account.

\section{Conclusion}

The principles of risk communication are a useful guide for managing fast-moving situations with high levels of public outrage, where public health strategies have implications for the health and wellbeing of large sections of society. Our recommendations on communication around COVID-19 and schooling have ongoing relevance over the coming months as the pandemic continues, and risks in schools, while likely to be minimal ${ }^{26}$, need to be managed and communicated carefully.

\section{Acknowledgements}

The authors thank Dr Penelope Robinson for assistance in researching the article.

\section{Peer review and provenance}

Externally peer reviewed, commissioned.

\section{Competing interests}

$J L$ has children in high school. $\mathrm{CH}$ has school-aged children and her husband teaches in a high school.

\section{Author contributions}

$J \mathrm{~L}$ and $\mathrm{CH}$ wrote the first draft and revised the paper.

\section{References}

1. Cauchemez S, Ferguson NM, Wachtel C, Tegnell A, Saour G, Duncan B, et al. Closure of schools during an influenza pandemic. Lancet Infect Dis. 2009;9(8):473-81.

2. Glass K, Barnes B. How much would closing schools reduce transmission during an influenza pandemic? Epidemiol. 2007;18(5):623-8.

3. Rashid H, Ridda I, King C, Begun M, Tekin H, Wood JG, et al. Evidence compendium and advice on social distancing and other related measures for response to an influenza pandemic. Paediatr Respir Rev. 2015;16(2):119-26.

4. Sadique MZ, Adams EJ, Edmunds WJ. Estimating the costs of school closure for mitigating an influenza pandemic. BMC Public Health. 2008;8(1):135.

5. Jaume D, Willén A. The long-run effects of teacher strikes: evidence from Argentina. Journal of Labor Economics. 2019;37(4):1097-139.

6. Li-Kim-Moy J YJ, Patel C, Beard FH, Chiu C, Macartney KK, Mcintyre, PB. Australian vaccine preventable disease epidemiological review series: Influenza 2006 to 2015. Commun Dis Intell. 2016;40(4):E482-95.

7. The Novel Coronavirus Pneumonia Emergency Response Epidemiology Team. The epidemiological characteristics of an outbreak of 2019 novel coronavirus diseases (COVID-19) - China, 2020. China CDC Weekly. 2020;2:1-10.

8. Australian Health Protection Principal Committee. Australian Health Protection Principal Committee (AHPPC) coronavirus (COVID-19) statement on 17 March 2020. Canberra: Australian Government Department of Health; 2020 [cited 2020 May 26]. Available from: www. health.gov.au/news/australian-health-protection-principalcommittee-ahppc-coronavirus-covid-19-statement-on-17march-2020-0

9. ABC News Breakfast. Norman Swan answers your coronavirus questions on pregnancy, asthma, pools and schools. Sydney: Australian Broadcasting Commission; 16 Mar 2020 [updated 6 April 2020; cited 2020 May 26]. Available from: www.abc.net.au/news/2020-03-16/ coronavirus-questions-on-pregnancy-asthma-pools-andschools/12058926

10. Essential Research. Sydney: Essential Media Communications; 2020. Essential report: coronavirus concerns; 2020 Apr 21 [cited 20208 May]. Available from: essentialvision.com.au/coronavirus-concerns-7 
11. Prime Minister of Australia. Update on coronavirus measures: media statement, 18 Mar 2020. Canberra: Prime Minister of Australia; 2020 [updated 18 March 2020, cited 2020 May 26]. Available from: www.pm.gov. au/media/update-coronavirus-measures

12. Sandman PM. Responding to community outrage: strategies for effective risk communication. Fairfax (VA): American Industrial Hygiene Association; 1993.

13. Bennett $P$, Calman $K$, editors. Risk communication and public health. Oxford: Oxford University Press; 1999.

14. Vaughan $\mathrm{E}$, Tinker $\mathrm{T}$. Effective health risk communication about pandemic influenza for vulnerable populations. Am J Public Health. 2009;99(S2):S324-32.

15. Brown N, Te Riele K, Shelley B. \& Woodroffe J. Learning at home during COVID-19: effects on vulnerable young Australians. Independent rapid response report. Hobart: University of Tasmania, Peter Underwood Centre for Educational Attainment; 2020 [cited 2020 May 26]. Available from: www.utas.edu.au/_data/assets/pdf_ file/0008/1324268/Learning-at-home-during-COVID-19updated.pdf

16.Lamb S, Maire Q, Doecke E, Macklin S, Noble K, Pilche S. Impact of learning from home on educational outcomes for disadvantaged children. Victoria: Centre for International Research on Education Systems and the Mitchell Institute Victoria University; 2020 [cited May 26]. Available from: www.mitchellinstitute.org.au/wp-content/ uploads/2020/04/Paper-to-Government-Impact-ofLearning-from-Home.pdf

17. National Centre for Immunisation Research and Surveillance. COVID-19 in schools - the experience in NSW. Preliminary report. Sydney: NCIRS; 2020 [cited 2020 May 26]. Available from: ncirs.org.au/sites/default/ files/2020-04/NCIRS\%20NSW\%20Schools\%20COVID_ Summary_FINAL\%20public_26\%20April\%202020.pdf

18. Han PKJ, Zikmund-Fisher BJ, Duarte CW, Knaus M, Black A, Scherer AM, et al. Communication of scientific uncertainty about a novel pandemic health threat: ambiguity aversion and its mechanisms. J Health Commun. 2018;23(5):435-44.
19. Essential Research. Sydney: Essential Media Communications; 2020. Essential report: views on opening schools following Covid-19; 2020 May 5 [cited 2020 May 8]. Available from: essentialvision.com.au/ views-on-opening-schools-following-covid-19

20. Hooker C, Capon A, Leask J. Communicating about risk: strategies for situations where public concern is high but the risk is low. Public Health Res Pract. 2017;27(1):e2711709

21. Department of Health. Australian health sector emergency response plan for novel coronavirus (COVID-19). Canberra: Australian Government DoH; 2020 [cited 2020 May 26]. Available from: www.health. gov.au/resources/publications/australian-health-sectoremergency-response-plan-for-novel-coronavirus-covid-19

22. Kickbusch I, Sakellarides C. Flu city - smart city: applying health promotion principles to a pandemic threat. Health Promot Int. 2006;21(2):85-7.

23. The New Daily. NSW schools to return full-time amid teacher concerns. Australia: The New Daily; 19 May 2020 [cited 2020 May 25]. Available from: thenewdaily.com.au/ news/2020/05/19/nsw-schools-return-coronavirus/

24. Besley JC. Public Engagement and the impact of fairness perceptions on decision favorability and acceptance. Science Communication. 2010;32(2):256-80

25. Tannenbaum MB, Hepler J, Zimmerman RS, Saul L, Jacobs S, Wilson K, et al. Appealing to fear: a metaanalysis of fear appeal effectiveness and theories. Psychol Bulletin. 2015;141(6):1178-204.

26. Viner RM, Russell SJ, Croker H, Packer J, Ward J, Stansfield C, et al. School closure and management practices during coronavirus outbreaks including COVID-19: a rapid systematic review. Lancet Child Adolesc Health. 2020;4(5):397-404.

\section{Copyright: (C) (i) (2) (2)}

(C) 2020 Leask and Hooker. This article is licensed under the Creative Commons Attribution-NonCommercial-ShareAlike 4.0 International Licence, which allows others to redistribute, adapt and share this work non-commercially provided they attribute the work and any adapted version of it is distributed under the same Creative Commons licence terms. See: www.creativecommons.org/licenses/by-nc-sa/4.0/ 